\title{
Effect of multiplicity of infection on Listeria monocytogenes pathogenicity for HeLa and Caco-2 cell lines
}

\author{
M. S. FRANCIS and C. J. THOMAS \\ Department of Microbiology and Immunology, University of Adelaide, GPO Box 498, Adelaide, South Australia, \\ 5005 Australia
}

\begin{abstract}
The significance of multiplicity of infection (moi) for invasiveness and intracellular multiplication of Listeria monocytogenes in Caco-2 and HeLa cell monolayers was investigated. A low moi (1:1) resulted in recovery of significantly more $L$. monocytogenes when these bacteria were used to infect either cell line. At high moi (100:1), the percentage recovery of bacteria was comparatively low, even after extensive invasion and intracellular multiplication. Microscopic analysis of Giemsa- and immunofluorescentstained infected monolayers revealed extensive cell disruption and exposure of the internalised bacteria to the bactericidal effect of gentamicin. By contrast, a low moi resulted in minimal cytopathic effects and evidence of cell to cell spread by $L$. monocytogenes was consistently observed in HeLa and $\mathbf{J 7 7 4}$, but not in Caco-2 cell lines. Nevertheless, the use of HeLa and Caco-2 cell monolayers enabled a clear distinction to be made between invasive ( $L$. monocytogenes) and non-invasive Listeria spp. (L. innocua, L. ivanovii, L. seeligeri, L. grayi, L. welshimeri and L. monocytogenes LLO19). The use of a low moi with HeLa cell monolayers provided a reliable tissue-culture model of infection for $L$. monocytogenes.
\end{abstract}

\section{Introduction}

Listeria monocytogenes is a ubiquitous gram-positive organism. It is commonly isolated from soil, decaying vegetation, silage, water and sewage [1], and is known to be responsible for perinatal infections, septicaemia and meningoencephalitis in man [2]. Elderly patients, pregnant women or individuals with predisposing conditions that compromise their immunity, such as transplants and malignancies such as lymphomas, are at particular risk [3]. Increased use of immunosuppressive drugs in the treatment of malignancies and organ transplantations, in addition to the current epidemic of AIDS, has considerably increased the population at risk to listerial infection. Epidemiological investigation of outbreaks of listeriosis has also demonstrated that infection results from ingestion of food contaminated with L. monocytogenes [4]. For these reasons, worldwide attention has been focused on this microorganism.

Received 20 Feb. 1996; accepted 18 March 1996.

Corresponding author: Dr C. J. Thomas.
L. monocytogenes has long been used as a model pathogen for the study of cell-mediated immunity. $L$. monocytogenes evades antibody and complementmediated lysis and killing by professional macrophages by entering, multiplying and persisting within host cells [5]. More recently, tissue-culture techniques have been applied to study the interactions between pathogen and host. This led to the development of invitro models of infection with $L$. monocytogenes involving tissue-culture monolayers. Gaillard et al. [6] first established an in-vitro model of penetration and intracellular growth of $L$. monocytogenes with the human enterocyte-like cell line Caco-2. L. monocytogenes was able to initiate entry into cells by inducing phagocytosis, followed by a period of bacterial intracellular multiplication. The use of this model for distinguishing between Listeria spp. on the basis of virulence was also described. Caco- 2 cells display typical enterocyte differentiation under standard culture conditions, such as the development of a brush border which contains some enzymes that are normally located in the small intestine $[7,8]$. For these reasons Caco- 2 cells were considered to be a suitable cell line for the analysis of $L$. monocytogenes virulence. 
Subsequent investigation showed that a wide variety of cell types are able to support the growth of $L$. monocytogenes, including macrophages, fibroblasts, epithelial cells, enterocytes and hepatocytes. The combined use of tissue-culture monolayer models of infection and electron and immunofluorescence microscopy provided insight into the cell biology of $L$. monocytogenes infections and facilitated the analysis of the bacterial genetic determinants responsible for pathogenesis $[6,9-15]$.

The Caco-2 cell line has become the most popular model for the analysis of $L$. monocytogenes virulence, primarily because of the typical enterocyte differentiation, and appears to be most susceptible to $L$. monocytogenes infection $[6,16,17]$. Pine et al. [18], in a comparison of the ability of L. monocytogenes to invade 12 different mammalian tissue-culture cell lines, observed that all were able to internalise L. monocytogenes, albeit to varying degrees, but Caco- 2 cells were at least 10 -fold more efficient at mediating internalisation. This unusually high efficiency of bacterial invasion has been suggested to be the result of enterocyte-like cells being the most probable initial site of entry in patients with foodborne listeriosis. Nevertheless, all comparative studies to date have neglected to consider the effect that multiplicity of infection (moi) has on the efficiency of L. monocytogenes to invade various cell types. In this study, the effect of moi on L. monocytogenes infection was investigated and the effectiveness of the HeLa epithelial cell line the Caco-2 enterocyte-like cell line as invitro models for studying the virulence of Listeria spp. was compared.

\section{Materials and methods}

\section{Bacterial strains, media and chemicals}

L. monocytogenes strain SLCC5764 (1/2a) was a gift from $\mathrm{H}$. Hof (University of Heidelberg, Mannheim, Germany). L. monocytogenes strain DRDC8 was an isolate from milk obtained from New South Wales Dairy Corporation Laboratories. L. monocytogenes LLO19 was a non-haemolytic phenotypic mutant of strain DRDC8 containing a Tn917-lacZ-cat86 insertion mediated by pTV53 [19], in the prfA gene encoding the positive regulatory factor of listeriolysin $O[20,21]$. All other Listeria spp. used in this study were acquired from the Institute of Medical and Veterinary Research, Adelaide, South Australia. Bacteria were cultivated routinely in Brain Heart Infusion (BHI) Agar or BHI Broth (Difco) at $37^{\circ} \mathrm{C}$ with aeration. L. monocytogenes LLO19 was cultivated in media containing erythromy$\operatorname{cin} 0.01 \mathrm{~g} / \mathrm{L}$ and lincomycin $0.025 \mathrm{~g} / \mathrm{L}$. Unless otherwise stated, all chemicals used in this study were purchased from either Ajax Chemicals, BDH Chemicals or Sigma Chemical Co.

\section{Tissue cultures and growth media}

Tissue-culture cell lines used in this study were the human colon adenocarcinoma enterocyte-like cell line Caco-2 (ATCC HTB 37), the human epithelial cell line HeLa (ATCC CCL 2.1) and the murine macrophagelike cell line J774 [22]. Caco-2 cells, used between passages 20 and 45, were cultured in Eagle's Minimal Essential Medium (EMEM) (Gibco Laboratories) supplemented with fetal bovine serum (Gibco) $10 \%$ $\mathrm{v} / \mathrm{v}$, glutamine $0.29 \mathrm{~g} / \mathrm{L}, \mathrm{NaHCO}_{3} 1.8 \mathrm{~g} / \mathrm{L}$, penicillin $0.1 \mathrm{~g} / \mathrm{L}$ and streptomycin $0.01 \mathrm{~g} / \mathrm{L}$. HeLa and $\mathrm{J} 774$ cells were cultured in Dulbecco's Modified Eagle's Medium (DMEM) (Gibco) supplemented with fetal bovine serum $5 \% \mathrm{v} / \mathrm{v}$, glutamine $0.29 \mathrm{~g} / \mathrm{L}, \mathrm{NaHCO}_{3} 3.6 \mathrm{~g} / \mathrm{L}$, penicillin $0.1 \mathrm{~g} / \mathrm{L}$ and streptomycin $0.01 \mathrm{~g} / \mathrm{L}$. Cells were cultured routinely in $75-\mathrm{ml}$ plastic tissue-culture flasks (Corning) at $37^{\circ} \mathrm{C}$ in a humidified atmosphere of $\mathrm{CO}_{2} 5 \% \mathrm{v} / \mathrm{v}$ in air. Semi-confluent monolayers (c. $5 \times 10^{6}$ cells $/ \mathrm{ml}$ ) for invasion assays were prepared by subculture of cell monolayers into 24-well tissueculture trays (Corning), containing acid-washed 12$\mathrm{mm}$ coverslips, to a final concentration of about $1 \times 10^{6}$ cells $/ \mathrm{ml}$ for Caco- 2 cells and $5 \times 10^{5}$ cells $/ \mathrm{ml}$ for HeLa and $\mathrm{J} 774$ cells, and incubating overnight.

\section{Invasion of tissue culture monolayers}

Cell monolayers were washed twice in the appropriate culture medium free of antibiotics. Cultures $(10 \mathrm{ml})$ of logarithmic-phase bacteria were washed once in saline $(\mathrm{NaCl} 8.5 \mathrm{~g} / \mathrm{L})$ and resuspended in $2 \mathrm{ml}$ of antibioticfree culture medium. Bacteria $(100 \mu \mathrm{l})$ diluted in antibiotic-free culture medium $\left(5 \times 10^{8}, 5 \times 10^{7}\right.$, $5 \times 10^{6}$ bacteria $/ \mathrm{ml}$ ), were overlayed on to the monolayers to achieve multiplicity of infection (moi) of $100: 1,10: 1$ and $1: 1$, respectively. Analysis of the colony forming units (cfu) applied to the monolayers was confirmed by plating suitable dilutions on $\mathrm{BHI}$ agar. Monolayers were incubated at $37^{\circ} \mathrm{C}$ in $\mathrm{CO}_{2} 5 \%$ $\mathrm{v} / \mathrm{v}$ in air for $2 \mathrm{~h}$, followed by three washes in antibiotic-free culture medium. A final incubation at $37^{\circ} \mathrm{C}$ in $\mathrm{CO}_{2} 5 \% \mathrm{v} / \mathrm{v}$ in air for $2 \mathrm{~h}$ in culture medium supplemented with gentamicin (Schering Corporation, USA) $0.04 \mathrm{~g} / \mathrm{L}$ was carried out to kill extracellular bacteria. Monolayers were washed twice in Hanks's Balanced Salts Solution. In addition, after the HeLa cell monolayers were infected with bacteria, they were centrifuged in a GPR centrifuge (Beckman) at $2500 \mathrm{rpm}$ for $15 \mathrm{~min}$ at room temperature (RT) to sediment the bacteria on to the monolayers. Furthermore, $\mathrm{J} 774$ monolayers were infected with bacteria at a moi of $1: 1$ and were incubated at $37^{\circ} \mathrm{C}$ in $\mathrm{CO}_{2} 5 \% \mathrm{v} / \mathrm{v}$ in air for $30 \mathrm{~min}$, followed by incubation for $30 \mathrm{~min}$ in medium containing gentamicin. Monolayers were finally washed in antibiotic-free DMEM.

Intracellular bacteria were recovered by lysis of the monolayers in $1 \mathrm{ml}$ of ice-cold Triton X-100 (0.1\% $\mathrm{v} / \mathrm{v}$ in sterile saline). The number of $\mathrm{cfu}$ recovered 
from cell lysates was determined by plating appropriate dilutions on BHI agar. The degree of bacterial invasion is represented by calculating the percentage of the original inoculum recovered after lysis of infected tissue-culture monolayers.

\section{Immunofluorescence microscopy}

Tissue-culture monolayers grown on coverslips were fixed in formaldehyde $3.7 \%$ in phosphate-buffered saline (PBS) $\left(\mathrm{NaCl} 8 \mathrm{~g} / \mathrm{L}, \quad \mathrm{KCl} 0.2 \mathrm{~g} / \mathrm{L}, \quad \mathrm{KH}_{2} \mathrm{PO}_{4}\right.$ $0.2 \mathrm{~g} / \mathrm{L}$ and $\mathrm{NaHPO}_{4}$ (anhydrous) $1.5 \mathrm{~g} / \mathrm{L}$ ) for at least $1 \mathrm{~h}$ at $4^{\circ} \mathrm{C}$. Monolayers were washed once in PBS and the cell membranes were permeabilised by the addition of Triton X-100 $0.1 \% \mathrm{v} / \mathrm{v}$ in PBS for $1 \mathrm{~min}$. Monolayers were washed six times with PBS, after which $10 \mu \mathrm{l}$ of diluted rabbit anti-Listeria $\mathrm{O}$ antiserum polyvalent serotypes 1,4 (Difco) was overlayed on to the monolayers and incubated at RT for $1 \mathrm{~h}$ in a humid chamber to prevent drying. Antisera was diluted in fetal bovine serum $10 \% \mathrm{v} / \mathrm{v}$ in PBS. Monolayers were washed another six times with PBS. To the monolayers, $10 \mu \mathrm{l}$ of diluted goat anti-rabbit IgGAM (H+L) fluorescein isothiocyanate (FITC) conjugate (The Binding Site Ltd, Birmingham) and $10 \mu \mathrm{l}$ of phalloidin

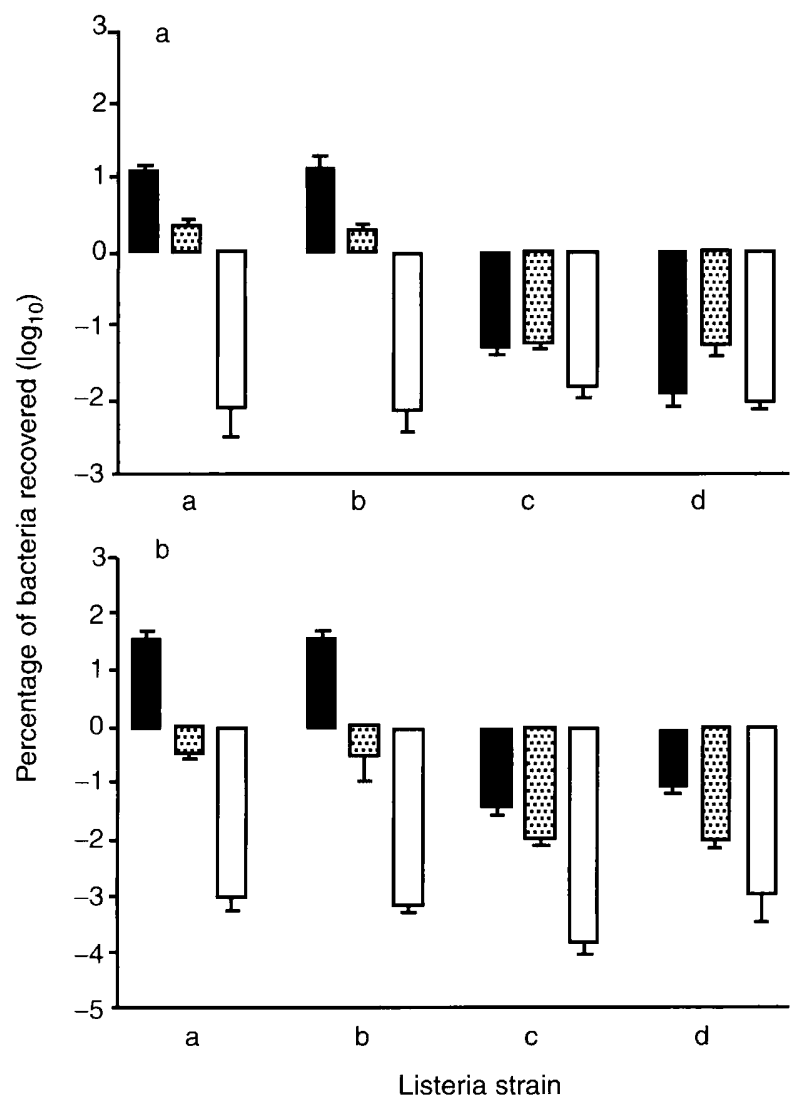

Fig. 1. Effect of moi ( $\square 1: 1 ; \square 10: 1 ; \square 100: 1)$ on percentage recovery of Listeria spp. from cell lysates after infection of Caco-2 (Panel a) and HeLa (Panel b) cell monolayers. a, L. monocytogenes DRDC8; b, L. monocytogenes SLCC5764; c, L. monocytogenes LLO19; d, L. innocua. Each column represents the mean of at least four independent experiments and bars indicate the SEM. rhodamine (TRITC) conjugate (Sigma) were applied and incubated at RT for $1 \mathrm{~h}$ in a humid chamber, followed by six washes in PBS. The coverslips were removed, air-dried, mounted face down on to microscope slides with $3 \mu \mathrm{l}$ of Moviol mounting medium and sealed with clear nail polish. Monolayers were examined with an Olympus BH-S microscope with a BH2-RFC UV fluorescent attachment and photographs were taken with Kodak Tmax 400 film.

\section{Giemsa staining for light microscopy}

Monolayers were fixed in cold $\left(-20^{\circ} \mathrm{C}\right)$ methanol for at least $5 \mathrm{~min}$. The coverslips were air-dried then stained in filter-sterilised Giemsa stain $(\mathrm{BDH})$ for at least $10 \mathrm{~min}$ at RT. Coverslips were washed in Giemsa buffer $\left(\mathrm{Na}_{2} \mathrm{HPO}_{4}\right.$ (anhydrous) $0.545 \mathrm{~g} / \mathrm{L}, \mathrm{KH}_{2} \mathrm{PO}_{4} 0.475 \mathrm{~g} / \mathrm{L}$ ) until the desired intensity of stain was achieved. Coverslips were air-dried, mounted face down on to microscope slides with DPX neutral mounting medium (Koch-Light Laboratories). Monolayers were viewed with an Olympus BH-2 light microscope and photographs were taken with Kodak Tmax 100 film.

\section{Statistical analysis}

Two-way analysis of variance was performed to compare the effect of moi on the potential of Listeria spp. to invade tissue-culture cell lines.

\section{Results}

Effect of moi on recovery of L. monocytogenes from Caco-2 and HeLa cell monolayers

The effects of inoculum size of L. monocytogenes on ability to invade and multiply in tissue-culture monolayers was investigated by infecting Caco-2 and HeLa cells with bacteria at moi of 100:1 (100 bacteria to 1 mammalian cell), $10: 1$ and 1:1. Numbers of bacteria recovered after infection were expressed as a percentage of the original inoculum and taken as an indication of the level of bacterial invasion.

When Caco-2 and HeLa cells were infected with $L$. monocytogenes strains DRDC8 and SLCC 5764, significantly more bacteria were recovered from monolayers when low moi were used $(100: 1<$ $10: 1<1: 1)(p<0.001)$ (Fig. 1). In the absence of a short centrifugation step, recovery of bacteria from infected HeLa cells was reproducibly low (data not shown). In addition, when the non-haemolytic $L$. monocytogenes strain LLO19, and the non-haemolytic non-pathogenic $L$. innocua were used to infect either cell line, consistently low recovery of bacteria was obtained. On the basis of these data, an moi of $1: 1$ was used in further experiments to compare the ability of Caco-2 and HeLa cell lines to discriminate between invasive and non-invasive isolates on the basis of the percentage of bacteria recovered from cell lysates. 
When monolayers were infected with either $L$. monocytogenes strain DRDC8 or SLCC 5764 at a moi of 1:1, these bacteria invaded at a similar level irrespective of the cell line used (Fig. 2A). Furthermore, similar numbers of bacteria/infected cell at $2 \mathrm{~h}$ post-infection were also obtained, independent of the cell line (Fig. 2B). However, neither cell line could reliably discriminate the invasive potential of strains DRDC8 or SLCC 5764 on the basis of bacterial recovery from infected monolayers. Nevertheless, both cell lines were able to discriminate between invasive and non-invasive isolates of Listeria (e.g., L. seeligeri, L. welshimeri, L. grayi, L. innocua and L. monocytogenes strain LLO19) $(\mathrm{p}<0.001)$.

\section{Microscopic analysis of Caco-2 and HeLa cell monolayers after infection with L. monocytogenes}

Although studies of invasiveness of isolates may provide an indication of the pathogenicity of that
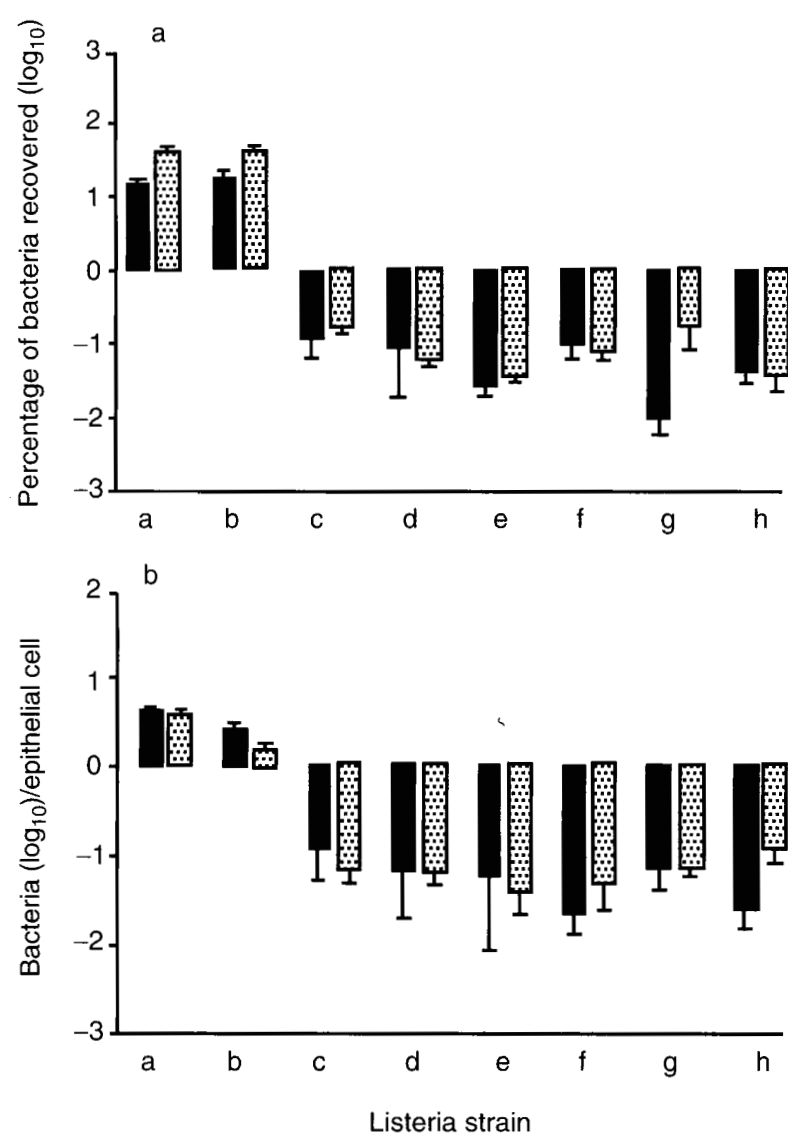

Fig. 2. Comparison of the extent of intracellular location of Listeria spp. in Caco-2 (ם) and HeLa (國) cell monolayers after infection with a moi of 1 bacterium to 1 cell. Panel a: percentage bacterial recovery from cell lysates; Panel b: number of bacteria/epithelial cell determined by light microscopy of Giemsa-stained, infected monolayers. a, L. monocytogenes DRDC8; b, L. monocytogenes SLCC5764; c, L. ivanovii; d, $L$. seeligeri; e, L. welshimeri; f, L. grayi; g, L. innocua; $\mathbf{h}$, L. monocytogenes LLO19. Each column represents the mean of at least four independent experiments and bars indicate the SEM. isolate, the latter does not always follow. Consequently, light microscopy was used to examine the ability of invasive isolates to induce cytopathic effects characteristic of virulent infections.

Giemsa-stained preparations of cells infected with either strain DRDC8 or SLCC 5764 at an moi of 100:1 showed that complete disruption of the cell monolayers had occurred. Few Caco-2 cells were identified and these showed extensive cytopathic changes when a moi of 10:1 was used (data not shown). However, at a moi of $1: 1$, intact cells that contained bacteria were detected. The morphology of these cells was similar to that of uninfected cells or cells infected with non-invasive organisms (Figs. 3A and B). By contrast, HeLa cell monolayers infected with either strain DRDC8 or strain SLCC 5764 at an moi of 10:1 showed marked loss of confluence and viable cells were heavily infected with bacteria and showed a rounded morphology with indistinct membranes (Fig. 3C). At a moi of 1:1, HeLa cell monolayers retained confluence with no apparent loss of viability, as observed with control cell monolayers (Figs. 3D and E). Furthermore, pseudopod structures used to facilitate bacterial cell to cell spread $[10,14]$ were readily identified.

Cell-to-cell spread during bacterial infection was confirmed by immunofluorescence techniques $[10,23$, 24]. Caco-2, J774 and HeLa cell lines infected at an moi of 1:1 with L. monocytogenes strains DRDC8 or SLCC 5764, demonstrated classical features indicative of bacterial-induced actin polymerisation and cell to cell spread (Fig. 4). Moreover, these features were more evident in the $\mathrm{J} 774$ and HeLa cells, and suggested more extensive bacterial parasitism within these cell lines. However, HeLa cells also revealed distinct patterns of filamentous actin, a feature not observed with either Caco-2 or J774 cells. Noninvasive strains of Listeria spp. and L. monocytogenes LLO19 were unable to multiply extensively within cells or polymerise actin or engage in cell-to-cell spread. These data suggested that the HeLa cell line is equally suitable for distinguishing between virulent and avirulent Listeria spp. based on its ability to support invasion and intracellular parasitism.

\section{Discussion}

Over the last decade, major advances have been made in understanding the role of virulence factors involved in the pathogenesis of Listeria. Development of tissueculture models of infection provided the catalyst for these rapid advances. In particular, the Caco- 2 colon carcinoma cell line has been used routinely in studies associated with $L$. monocytogenes infection [6,11, $12,17,25]$. Caco-2 cells are considered to be significantly more sensitive to $L$. monocytogenes invasion 

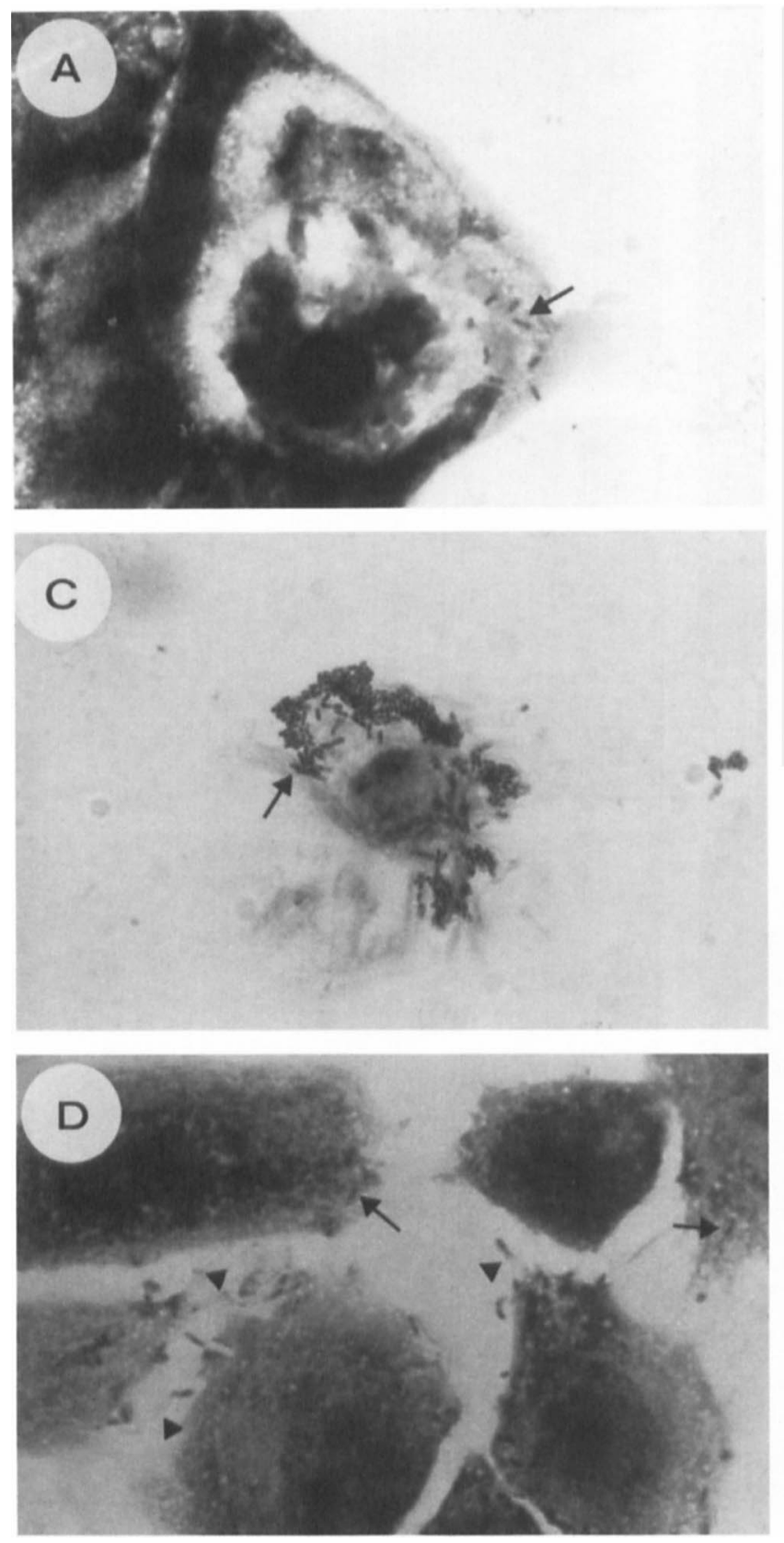

Fig. 3. Light photomicrographs $(\times 1000)$ of Giemsa-stained Caco-2 and HeLa cells at $4 \mathrm{~h}$ after infection with Listeria spp. a, Caco-2 cells infected at a moi of 1 bacterium to 1 cell $(1: 1)$ with $L$. monocytogenes DRDC8; b, Caco-2 cells infected with L. monocytogenes LLO19; c, HeLa cells infected at a moi of 10:1 with L. monocytogenes DRDC8; d, HeLa cells infected at a moi of 1:1 with L. monocytogenes DRDC8; e, HeLa cells infected at a moi of 10:1 with $L$. monocytogenes LLO19. Arrows indicate intracellular bacteria. Arrowheads indicate pseudopod-like structures indicative of cell to cell spread of $L$. monocytogenes. Micrographs shown are representative of the degree of monolayer confluence of tissue culture cells.

than other human epithelial cell lines including $\mathrm{HeLa}$ Henle 407 and Hep-2 [18, 26]. This increased sensitivity is assumed to be due to features unique to Caco-2 morphology $[7,8]$.

This study showed that permissiveness of L. monocytogenes to invade either HeLa or Caco- 2 cell lines is directly dependent upon the assay conditions. To establish significant bacterial invasion of the HeLa cell line, a centrifugation step was incorporated into the infection protocol. Under these conditions it was
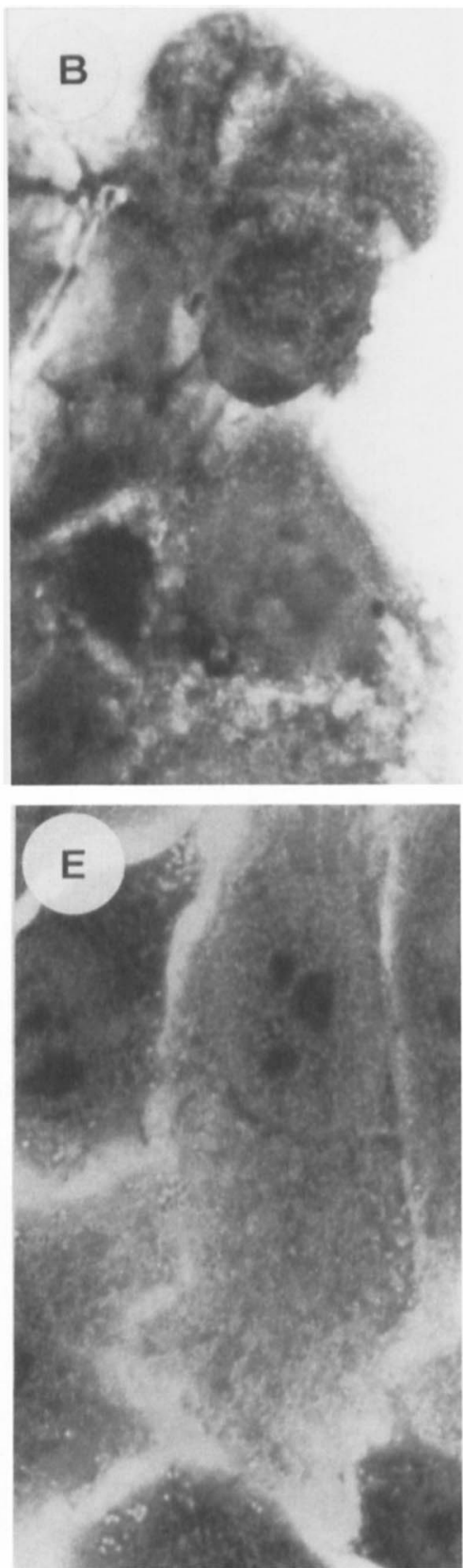

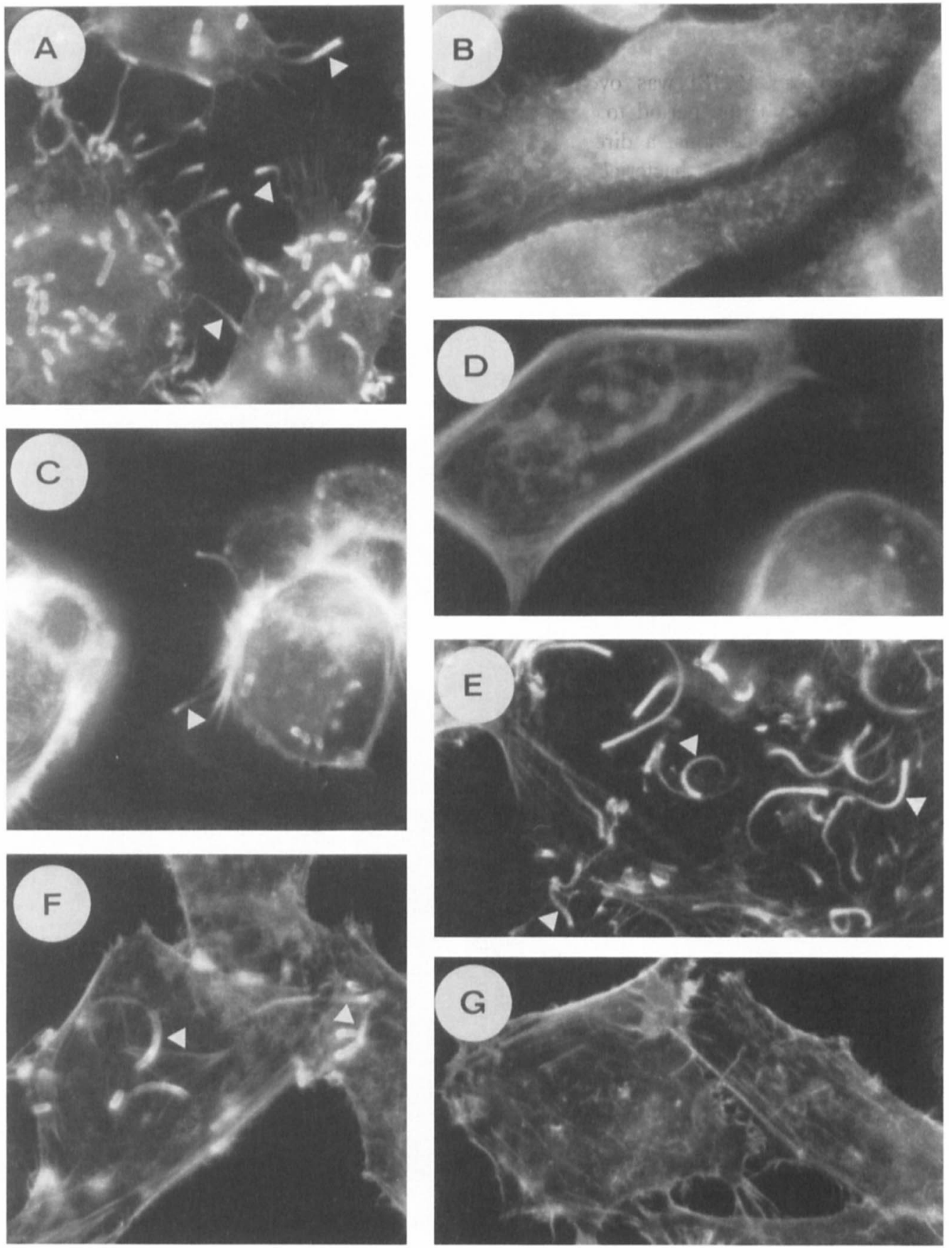

Fig. 4. Photomicrographs $(\times 1000)$ of phalloidin rhodamine conjugate-stained J774, Caco-2 and HeLa cells after infection with Listeria spp. a, J774 cells infected at a moi of 1 bacterium to 1 cell $(1: 1)$ with L. monocytogenes DRDC8; b, J774 cells infected at a moi of 1:1 with L. monocytogenes LLO19; c, Caco-2 cells infected at a moi of 1:1 with L. monocytogenes DRDC8; d, Caco-2 cells infected at a moi of 1:1 with L. monocytogenes LLO19; e, HeLa cells infected at a moi of 10:1 with L. monocytogenes DRDC8; $\mathbf{f}$, HeLa cells infected at a moi of $1: 1$ with L. monocytogenes DRDC8; g, HeLa cells infected at a moi of 1:1 with L. monocytogenes LLO19. Arrowheads indicate pseudopod-like structures indicative of cell-to-cell spread of $L$. monocytogenes.

concentrations of gentamicin contained in the culture medium that prevented recovery of viable bacteria from cell lysates. Gentamicin is unable to permeate through cell membranes, and is, therefore, used routinely in tissue-culture models of infection to kill extracellular bacteria [27-30]. This aspect has been overlooked in earlier studies that described recovery and intracellular multiplication of L. monocytogenes in Caco-2 monolayers after infection with high moi
$[6,24,31]$. Heavily infected cells probably lyse due to excessive structural stress imposed by high numbers of intracellular bacteria. In contrast, lytic activity induced by bacterial enzymes is unlikely to result in cell membrane disruption. For example, cytolytic activity of listeriolysin $\mathrm{O}$, a pore-forming haemolysin responsible for membrane disruption [32] is restricted to the phagolysosome, where an internal $\mathrm{pH}$ of 5.5 is necessary for optimal activity [33]. 
The significant monolayer disruption noted after prolonged exposure (16-24 h) of monolayers to high moi of $L$. monocytogenes $[6,18]$ was overcome by routinely limiting the incubation period to $4 \mathrm{~h}$ with a moi of $1: 1$. Under these conditions, a direct correlation between low moi and high bacterial recoveries from infected monolayers was observed. In our hands, at least, careful selection of moi is essential to provide a more appropriate method of determining the ability of an organism to invade and multiply within tissueculture cells. Furthermore, HeLa and Caco-2 cells were equally efficient at discriminating between invasive (L. monocytogenes) and non-invasive Listeria spp. (L. ivanovii, L. seeligeri, L. welshimeri, L. grayi, L. innocua and L. monocytogenes LLO19), a feature observed in other tissue-culture models of infection $[6,18,34,35]$. While the results of the present study agree with previous suggestions that Caco-2 cells are more susceptible to invasion by $L$. monocytogenes $[6,17,18,26]$, we do not agree with the view that this cell line is the most suitable for the analysis of listerial invasion. Any advantages of Caco- 2 cells over HeLa cells can be overcome by employing a combination of a centrifugation step, short incubation periods, and low moi. With this modified infection process, the utility of the HeLa cell line for studying L. monocytogenes infection has been clearly demonstrated.

Invasiveness of an organism is not the only requirement for establishing an infection. Virulence of $L$. monocytogenes also depends on ability to spread from cell to cell. Consequently, the utility of HeLa cells as a suitable tissue culture model of infection was confirmed by assessment of pathogenicity of Listeria spp. with immunofluorescence microscopy to compare the ability of Listeria spp. to engage in cell-to-cell spread. In addition to Caco-2 and HeLa cells, the murine macrophage cell line $\mathrm{J} 774$ was included in this study. These cells have been used extensively to study characteristics of $L$. monocytogenes infection $[14,24,36-38]$. As expected, L. monocytogenes contained within $\mathrm{J} 774$ cells displayed a high degree of filamentous actin polymerisation and cell to cell spread in comparison to infected Caco-2 and HeLa cell lines. Nevertheless, L. monocytogenes-induced filamentous actin polymerisation and pseudopodia-like structures were more distinctive in HeLa cells than in Caco-2 cells, suggesting a greater parasitism of pathogenic L. monocytogenes for the HeLa cell line. This effect may result from a greater rate of growth in HeLa cells.

Variations in bacterial growth rates within different cell lines have been described previously. In particular, an intracellular doubling time of c. 90 min has been reported for L. monocytogenes in Caco-2 cells [6]. However, a doubling time of $c$. 60 min was observed in various cell lines including the epithelial cell line Henle 407 [29]. The ability of Listeria strains to multiply intracellularly is used routinely as a measure of bacterial virulence [39]. It follows that enhanced intracellular multiplication of an organism is most likely reflected by an increase in intracellular parasitism. This study did not seek to determine bacterial growth rates within HeLa and Caco-2 cells. However, these data could help in understanding why $L$. monocytogenes shows greater parasitism for HeLa cells. While Caco-2 cells may be more efficient at mediating invasion $[6,17,18,26]$, HeLa cells may promote rapid intracellular growth of $L$. monocytogenes.

The isogenic mutant L. monocytogenes strain LLO19 was included as a negative control. This strain contains a Tn917 insertion in the gene encoding the positive regulatory factor $\operatorname{PrfA}$, which is responsible for expression of a number of necessary virulence determinants of $L$. monocytogenes [20,21,31] and is essential for the establishment of infection [40]. As expected, this mutant demonstrated significantly reduced invasive potential and was unable to engage in cell to cell spread. Furthermore, the viability of the cell monolayers was not compromised by infection with strain LLO19. This suggests that L. monocytogenes does not shed toxic by-products during in-vitro growth that may contribute to cytopathic effects on tissue-culture cells. Interestingly, the animal pathogen L. ivanovii was unable to polymerise host cell actin and was significantly less invasive than $L$. monocytogenes. Similarly, L. ivanovii is unable to invade the mouse embryo fibroblast cell line 3T6 [35]. No evidence of cytopathogenicity for hybridoma and myeloma cell lines has been observed, even after prolonged infection [34]. However, other studies have reported invasion of cell lines and polymerisation of host cell actin $[6,16]$. Although we have no explanation for these apparent anomalies, strain variation among $L$. ivanovii isolates may contribute to the different responses observed.

In conclusion, the results of this study show the importance of moi in tissue-culture models of infection. Indeed, under the conditions described, $\mathrm{HeLa}$ and Caco-2 cells were equally capable of discriminating between invasive and non-invasive Listeria spp. Furthermore, HeLa cells provided an easier means to distinguish between pathogenic and non-pathogenic Listeria spp. by immunofluorescence microscopy. In contrast to Caco-2 cells, certain features of HeLa cells, including flat morphology, large cytoplasmic area and ease of culture, make this the preferred cell line for analysis of pathogenicity of Listeria spp. by tissue-culture models of infection.

This work was supported by the Australian Chicken Meat Research and Development Council and in part by the Australian Dairy Research Corporation. We thank Barbara McClure and Melinda Lucic for the construction of L. monocytogenes LLO19. M.S.F. is a recipient of an Australian Chicken Meat Research and Development Council Postgraduate Scholarship. 


\section{References}

1. Watkins J, Sleath KP. Isolation and enumeration of Listeria monocytogenes from sewage, sewage sludge and river water. $J$ Appl Bacteriol 1981; 50: 1-9.

2. Gellin BG, Broome CV. Listeriosis. JMA 1989; 261: 1313 1320 .

3. Nieman RE, Lorber, B. Listeriosis in adults: a changing pattern. Report of eight cases and review of the literature, 1968-1978. Rev Infect Dis 1980; 2: 207--227.

4. Wehr HM. Listeria monocytogenes - a current dilemma. $J$ Assoc Off Anal Chem 1987; 70: 769-772.

5. Mackaness GB. The influence of immunologically committed lymphoid cells on macrophage activity in vivo. $J$ Exp Med 1962; 129: 973-992.

6. Gaillard J-L, Berche P, Mounier J, Richard S, Sansonetti P. In vitro model of penetration and intracellular growth of Listeria monocytogenes in the human enterocyte-like cell line Caco- 2 Infect Immun 1987; 55: 2822-2829.

7. Pinto M, Robine-Leon S, Appay MD et al. Enterocyte-like differentiation and polarization of the human colon carcinoma cell line Caco-2 in culture. Biol Cell 1983; 47: 323-330.

8. Rousset M. The human colon carcinoma cell lines HT-29 and Caco-2: two in vitro models for the study of intestinal differentiation. Biochimie 1986; 68: 1035-1040.

9. De Chastellier C, Berche P. Fate of Listeria monocytogenes in murine macrophages: evidence for simultaneous killing and survival of intracellular bacteria. Infect Immun 1994; 64: 543553.

10. Dabiri GA, Sanger JM, Portnoy DA, Southwick FS. Listeria monocytogenes moves rapidly through the host-cell cytoplasm by inducing directional actin assembly. Proc Natl Acad Sci USA 1990; 87: 6068-6072.

11. Karunasagar I, Senghaas B, Krohne G, Goebel W. Ultratructural study of Listeria monocytogenes entry into cultured human colonic epithelial cells. Infect Immun 1994; 62: 3554 3558.

12. Mounier J, Ryter A, Coquis-Rondon M, Sansonetti PJ Intracellular and cell-to-cell spread of Listeria monocytogenes involves interaction with $\mathrm{F}$-actin in the enterocyte-like cell line Caco-2. Infect Immun 1990; 58: 1048-1058

13. Sun AN, Camilli A, Portnoy DA. Isolation of Listeria monocytogenes small-plaque mutants defective for intracellular growth and cell-to-cell spread. Infect Immun 1990; 58: 3770 3778 .

14. Tilney LG, Portnoy DA. Actin filaments and the growth, movement, and spread of the intracellular bacterial parasite Listeria monocytogenes. J Cell Biol 1989; 109: 1597-1608.

15. Tilney LG, Tilney MS. The wily ways of a parasite: induction of actin assembly by Listeria. Trends Microbiol 1993; 1: 2531.

16. Karunasagar I, Krohne G, Goebel W. Listeria ivanovii is capable of cell-to-cell spread involving actin polymerization. Infect Immun 1993; 61: 162-169.

17. Kathariou S, Pine L, George V, Carlone GM, Holloway BP. Nonhemolytic Listeria monocytogenes mutants that are also noninvasive for mammalian cells in culture: evidence for coordinate regulation of virulence. Infect Immun 1990; 58 3988-3995.

18. Pine L, Kathoriou S, Quinn F, George V, Wenger JD, Weaver RE. Cytopathogenic effects in enterocytelike Caco-2 cells differentiate virulent from avirulent Listeria strains. $J$ Clin Microbiol 1991; 29: 990-996.

19. Youngman P, Perkins JB, Sandman K. Use of Tn917-mediated transcriptional fusions to $l a c Z$ and $c a t-86$ for the identification and study of regulated genes in the Bacillus subtilis chromosome. In: Hoch JA, Setlow P (eds) Molecular biology of microbial differentiation. American Society for Microbiology, Washington, DC 1985: 47-54.

20. Chakraborty T, Leimeister-Wächter M, Domann E et al. Coordinate regulation of virulence genes in Listeria monocytogenes requires the product of the prfA gene. J Bacteriol 1992 ; 174: $568-574$
21. Leimeister-Wächter M, Haffner C, Domann E, Goebel W, Chakraborty $\mathrm{T}$. Identification of a gene that positively regulates expression of listeriolysin, the major virulence factor of Listeria monocytogenes. Proc Natl Acad Sci USA 1990; 87: 8336-8340.

22. Rathjen DA, Geczy CI. Conditioned medium from macrophage cell line supports the single-cell growth of hybridomas. Hybridoma 1986; 5: 255-261.

23. Domann E, Wehland J, Rohde $\mathrm{M}$ et al. A novel bacterial virulence gene in Listeria monocytogenes required for host cell microfilament interaction with homology to the proline-rich region of vinculin. EMBO $J$ 1992; 11: 1981-1990.

24. Niebuhr K, Chakraborty $\mathrm{T}$, Rohde $\mathrm{M}$ et al. Localization of the ActA polypeptide of Listeria monocytogenes in infected tissue culture cell lines: ActA is not associated with actin "comets". Infect Immun 1993; 61: 2793-2802.

25. Quinn F, Pine L, White E, George V, Gutekunst K, Swaminathan B. Immunogold labelling of Listeria monocytogenes virulence-related factors within Caco-2 cells. Res Microbiol 1993; 144: 597-608.

26. Gaillard J-L, Berche P, Frehel C, Gouin E, Cossart P. Entry of $L$. monocytogenes into cells is mediated by internalin, a repeat protein reminiscent of surface antigens from gram-positive cocci. Cell 1991; 65: 1127-1141.

27. Lissner CR, Swanson RN, O'Brien AD. Genetic control of the innate resistance of mice to Salmonella typhimurium: expression of the Ity gene in peritoneal and splenic macrophages isolated in vitro. J Immunol 1983; 131: 3006-3013.

28. Havell EA. Synthesis and secretion of interferon by murine fibroblasts in response to intracellular Listeria monocytogenes. Infect Immun 1986; 54: 787-792.

29. Portnoy DA, Jacks PS, Hinrichs DJ. Role of hemolysin for the intracellular growth of Listeria monocytogenes. J Exp Med 1988; 167: 1459-1471

30. Vaudaux P, Waldvogel FA. Gentamycin antibacterial activity in the presence of human polymorphonuclear leukocytes. Antimicrob Agents Chemother 1979; 16: 743-749.

31. Dramsi S, Kocks C, Forestier C, Cossart P. Internalin-mediated invasion of epithelial cells by Listeria monocytogenes is regulated by the bacterial growth state, temperature and the pleiotropic activator prfA. Mol Microbiol 1993; 9: 931-941.

32. Cossart P, Mengaud J. Listeria monocytogenes. A model system for the molecular study of intracellular parasitism. Mol Biol Med 1989; 6: 463-474.

33. Geoffroy C, Gaillard J-L, Alouf JE, Berche P. Purification, characterization, and toxicity of the sulfhydryl-activated hemolysin listeriolysin $\mathrm{O}$ from Listeria monocytogenes. Infect Immun 1987; 55: 1641-1646.

34. Bhunia AK, Steele PJ, Westbrook DG, Bly LA, Maloney TP, Johnson MG. A six-hour in vitro virulence assay for Listeria monocytogenes using myeloma and hybridoma cells from murine and human sources. Microb Pathog 1994; 16: 99-110.

35. Kuhn M, Kathariou S, Goebel W. Hemolysin supports survival but not entry of the intracellular bacterium Listeria monocytogenes. Infect Immun 1988; 56: 79-82.

36. Bielecki J, Youngman P, Connelly P, Portnoy DA. Bacillus subtilis expressing a haemolysin gene from Listeria monocytogenes can grow in mammalian cells. Nature 1990; 345: 175-176.

37. Kocks C, Gouin E, Tabouret M, Berche P, Ohayon H, Cossart P. L. monocytogenes-induced actin assembly requires the act $A$ gene product, a surface protein. Cell 1992; 68: 521-531.

38. Raybourne RB, Bunning VK. Bacterium-host cell interactions at the cellular level: fluorescent labeling of bacteria and analysis of short-term bacterium-phagocyte interaction by flow cytometry. Infect Immun 1994; 62: 665-672.

39. Jones S, Portnoy DA. Intracellular growth of bacteria. Methods Enzymol 1994; 236: 463-467.

40. Freitag NE, Rong L, Portnoy DA. Regulation of the prfA transcriptional activator of Listeria monocytogenes: multiple promoter elements contribute to intracellular growth and cellto-cell spread. Infect Immun 1993; 61: 2537-2544. 